\title{
Long term stability of Oligo (dT) 25 magnetic beads for the expression analysis of Euglena gracilis for long term space projects
}

\author{
Ina Becker ${ }^{\mathrm{a}, *}$, Sebastian M. Strauch ${ }^{\mathrm{a}}$, Jens Hauslage ${ }^{\mathrm{b}}$, Michael Lebert ${ }^{\mathrm{a}}$ \\ a Department of Cell Biology, Friedrich-Alexander-University Erlangen-Nürnberg, Staudtstrasse 5, Erlangen 91058, Germany \\ ${ }^{\mathrm{b}}$ German Aerospace Centre (DLR), Institute of Aerospace Medicine, Linder Höhe, Cologne 51147, Germany
}

\section{A R T I C L E I N F O}

\section{Article history:}

Received 22 December 2016

Accepted 18 February 2017

\section{Keywords:}

Euglena gracilis

Stability

Magnetic beads

Lysis buffer

DTT

\begin{abstract}
A B S T R A C T
The unicellular freshwater flagellate Euglena gracilis has a highly developed sensory system. The cells use different stimuli such as light and gravity to orient themselves in the surrounding medium to find areas for optimal growth. Due to the ability to produce oxygen and consume carbon dioxide, Euglena is a suitable candidate for life support systems. Participation in a long-term space experiment would allow for the analysis of changes and adaptations to the new environment, and this could bring new insights into the mechanism of perception of gravity and the associated signal transduction chain. For a molecular analysis of transcription patterns, an automated system is necessary, capable of performing all steps from taking a sample, processing it and generating data. One of the developmental steps is to find long-term stable reagents and materials and test them for stability at higher-than-recommended temperature conditions during extended storage time. We investigated the usability of magnetic beads in an Euglena specific lysis buffer after addition of the RNA stabilizer Dithiothreitol over 360 days and the lysis buffer with the stabilizer alone over 455 days at the expected storage temperature of $19^{\circ} \mathrm{C}$. We can claim that the stability is not impaired at all after an incubation period of over one year. This might be an interesting result for researchers who have to work under non-standard lab conditions, as in biological or medicinal fieldwork.
\end{abstract}

(c) 2017 Published by Elsevier Ltd on behalf of The Committee on Space Research (COSPAR).

\section{Introduction}

Euglena gracilis is a motile and photosynthetic unicellular freshwater flagellate, able to live either autotrophic or heterotrophic. $\mathrm{Eu}$ glena gracilis cells can orient themselves in their habitat with respect to different stimuli (Häder et al., 2003). The cells can detect a wide range of light intensities. At low light levels, the cells swim towards the light source (positive phototaxis), whereas, in presence of excessive light, the cells swim away from it (negative phototaxis). The light perception is accomplished by a blue light photoreceptor in the photo-sensing organelle called paraxonemal body (Häder, 1987), which is a swelling of the emerged flagellum inside the reservoir (Ghetti et al., 1985). PAC, a photo-activated adenylyl cyclase, able to convert adenosine-triphosphate (ATP) into the second messenger cyclic adenosine-monophosphate (cAMP), is considered as the first step in the signal transduction chain of phototaxis (Iseki et al., 2002), and is able to affect different downstream targets (Ntefidou et al., 2003).

\footnotetext{
* Corresponding author.

E-mail addresses: ina.becker@fau.de (I. Becker), sebastian.m.strauch@fau.de (S.M. Strauch), jens.hauslage@dlr.de (J. Hauslage), michael.lebert@fau.de (M. Lebert).
}

In absence of light, the cells orient themselves with respect to the gravity vector. This behavior called gravitaxis is mainly a physiological mechanism and was investigated by means of microgravity experiments, such as parabolic flights (Strauch et al., 2010), TEXUS sounding rocket campaigns (Richter et al., 2001), IML-2 on the Space Shuttle (Häder et al., 1995), and FOTON M-2 (Häder et al., 2006) and Shenzhou 8 (Nasir et al., 2014), both satellites with sample return capability.

A young Euglena cell orients itself by means of positive gravitaxis, but this alters into negative gravitaxis as soon as they get older (Wayne et al., 1992). The cells have no intracellular statoliths for graviperception (other than e.g. Loxodes (Hemmersbach and Häder, 1999) or Chara (Braun, 2002), so it is supposed that the whole cell acts as a statolith, presumed that the surrounding medium has a lower specific density than the cell. The opening of mechano-sensitive channels leads to an increase in intracellular calcium level, which is supposed to activate a calcium binding protein called Calmodulin (CaM) (Daiker et al., 2010). This in turn is used to activate a protein kinase A (PKA) (Daiker et al., 2011), which is able to phosphorylate other proteins and thus the flagellar beating pattern is altered. The genes involved in gravitaxis were found by means of RNA interference studies. However, the 
signal transduction chain underlying gravitaxis is not yet fully understood.

In recent years, we exposed Euglena to prolonged periods of microgravity during the FOTON M-2, Shenzhou 8 and Bion M-1 missions. In the respective setups, Euglena was not merely the object of gravi-biological studies; we designed artificial ecosystems with Euglena as producer (or co-producer together with Ceratophyllum), fish and/or snails as consumers and allowed for the establishment of bacterial communities as decomposers in ubiquitous biofilms or dedicated filter compartments. Since Euglena prefers ammonia to nitrate as primary nitrogen source, it does not compete with higher plants in the same system, but rather provides some detoxification by reducing the ammonia level.

As a next step for a long-term experiment in space, the analysis of molecular and physiological changes in Euglena cells could elucidate the mechanisms of graviperception and clarify the role of components of the attached signal transduction chain. We developed a concept for a so-called space-PCR in order to monitor expression levels of genes involved in gravitaxis and photosynthesis along with house-keeping genes. In our approach, magnetic beads will trap the messenger RNA (mRNA) of lysed Euglena cells. The trapping of mRNA is based on the base-pairing between the OligodT sequence, which is bound to the surface of the beads and the poly-A tail of the mRNA. To accumulate the beads with the annealed mRNA, a magnet is placed at the side of the silicon tube. Subsequently, cDNA synthesis is performed directly on the beads. The expression level of various genes is then detected with microarrays.

In an unmanned space mission, certain facts need to be considered: restricted space, long waiting periods between the last access and launch, and environmental conditions. Minimizing the number of different reagents by using a common reagent or solution for most purposes will allow for the reduction of the installation of different tanks and pumps, etc., thereby saving space. The function of different lysis buffers for cell lysis and extraction of RNA, beads, and as well as their long-term stability and usability in different conditions needs to be determined. Information about the performance of reagents after non-standard storage conditions seem to be unknown to the manufacturers and/or regarded irrelevant.

Here, the stability analysis of two different mixtures is reported over a longer period. The first mixture consists of Euglena specific lysis buffer (RLA) mixed with the RNA stabilizer Dithiothreitol (DTT) and was tested for its ability to keep the RNA stable at $19^{\circ} \mathrm{C}$. The second mixture consists of RLA-lysis buffer, DTT and the magnetic beads, to evaluate the capability of the magnetic beads to capture mRNA at different time points with similar concentration and quality at $19{ }^{\circ} \mathrm{C}$ as well as at $4{ }^{\circ} \mathrm{C}$ for control.

\section{Materials and methods}

\subsection{Overview over the experimental procedure}

Finding the optimal beads for this experiment was the first step in the experimental procedure since the mRNA will not be isolated in normal Eppendorf tubes but in a silicon tube. Next, different lysis buffer for the proper lysis of Euglena cells had to be tested. Considering the fact that there will be no possibility to centrifuge cells in space, the optimal buffer-to-cells-ratio had to be found to get the best results. The manufacturer recommends pelleting cells before lysis, which is not possible in this approach. Afterwards RNA stabilizing additives in the lysis buffer, like $\beta$-Mercaptoethanol or Dithiothreithol, were tested. Finally, the optimal incubation time of lysis buffer, additives and Euglena cells had to be determined to obtain the best results.
Only after all this steps it was possible to set up the stability tests. Considering the different effects of the magnetic beads, the lysis buffer and the additives in the mixture, the stability test \#1 was used as a control to see that the lysis buffer is not impaired by adding the additive at the expected temperature of $19^{\circ} \mathrm{C}$.

\subsection{Growth and maintenance of Euglena gracilis}

Euglena was cultured in minimal medium (MM (Checcucci, 1976)) under continuous white light illumination of $20 \mathrm{~W} \mathrm{~m}^{-2}$ at $18^{\circ} \mathrm{C} \pm 2{ }^{\circ} \mathrm{C}$. Stock cultures of the strain were maintained in minimal liquid, as well as agar slants and plates, and propagated twice before use.

\subsection{Chemicals and reagents}

Two different beads tested for the mRNA isolation included the Dynabeads ${ }^{\circledR}$ Oligo (dT) 25 from Invitrogen (Carlsbad, USA) and the MagJET beads from ThermoScientific (Waltham, USA). The beads are uniform and paramagnetic polymer particles with Oligo dT sequences covalently coupled to the bead surface.

The three different lysis buffers tested included the RLA buffer (Promega, Madison, USA), RLC and RLT buffer (both Qiagen, Hilden, Germany). For the stabilization of RNA after lysis, two different additives were mixed with the lysis buffer and tested, DLDithiothreitol (DTT, $\geq 98 \%$ ) and 2-mercaptoethanol (both SigmaAldrich, St. Louis, USA).

\subsection{Preparation of solutions and their storage}

Stability test mixture \#1:

$33 \mathrm{~mL}$ of the RLA-lysis buffer was mixed with $660 \mu \mathrm{L}$ of DTT and stored at $19^{\circ} \mathrm{C}$ in the dark. The mixtures volume was sufficient for 15 months when measuring triplet samples every second week. Degradation of RNA by RNases, which are extremely stable and active, must be taken into account when working with RNA. During the isolation procedure, intracellular RNases are released which have to be rapidly inactivated to obtain high-quality RNA. DTT reduces the disulfide bonds of the RNase and thus destroys the native conformation required for enzyme functionality.

Stability test mixture \#2:

$12 \mathrm{~mL}$ of the RLA-lysis buffer, $240 \mu \mathrm{L}$ of DTT and $720 \mu \mathrm{L}$ Dynabeads ${ }^{\circledR}$ were mixed. Half of the mixture was stored at $19{ }^{\circ} \mathrm{C}$ and the other half as a control at $4^{\circ} \mathrm{C}$. Both solutions were kept in dark and samples were measured in triplets every second month.

\section{Isolation procedure:}

RNA isolation with RNeasy plant mini kit

For RNA isolation, $350 \mu \mathrm{L}$ stability test mixture \#1 (22 $\mu \mathrm{L}$ DTT in $328 \mu \mathrm{L}$ lysis buffer) was incubated with $5 \times 10^{5}$ Euglena gracilis cells in a volume of $350 \mu \mathrm{L}$ MM. The RNA was isolated using the RNeasy Plant Mini Kit from Qiagen (Hilden, Germany) and eluted in $30 \mu \mathrm{L}$ RNAse free water. The RNA concentration and ratio was measured using a NanoDrop spectrophotometer (ThermoScientific, Waltham, USA). RNA was transcribed into cDNA with the QuantiTect Transcription Kit (Qiagen, Hilden, Germany). RNA and cDNA quality was checked on a $1 \%$ agarose gel. cDNA quality was also tested in a polymerase chain reaction (PCR) with primers for $\alpha$ Tubulin, a housekeeping gene of Euglena gracilis.

mRNA isolation with Dynabeads ${ }^{\circledR}$ Oligo (dT) 25

For mRNA isolation, $350 \mu \mathrm{L}$ of stability test mixture \#2 (the magnetic beads and the RNA stabilizer mixed with the lysis buffer) was incubated with $350 \mu \mathrm{L}$ RNA (1000 ng in total) for different time periods at room temperature. The isolation took place in a silicon tube with the help of a magnet placed on the outside: the mixture was passed through a silicon tube and the beads accumulated next 
to the magnet on the tube wall. Beads were washed by suspending them first in $100 \mu \mathrm{L}$ wash buffer A ( $10 \mathrm{mM}$ Tris- $\mathrm{HCl}, \mathrm{pH} 7.5$, $0.15 \mathrm{M} \mathrm{LiCl}, 1 \mathrm{mM}$ EDTA, $0.1 \%$ LiDS) and afterwards in wash buffer B (10 mM Tris- $\mathrm{HCl}, \mathrm{pH} 7.5,0.15 \mathrm{M} \mathrm{LiCl}, 1 \mathrm{mM}$ EDTA $10 \mathrm{mM}$ Tris$\mathrm{HCl}, \mathrm{pH} 7.5$ ). Aliquots of $50 \mu \mathrm{L}$ of the beads in wash buffer B were removed for RNA elution and the other $50 \mu \mathrm{L}$ for cDNA synthesis with components of the QuantiTect Reverse Transcription Kit from Qiagen (Hilden, Germany).

For RNA elution, the beads were resuspended in $10 \mu \mathrm{L}$ Tris- $\mathrm{HCl}$, heated up for $2 \mathrm{~min}$ at $77^{\circ} \mathrm{C}$ and the free mRNA in the supernatant was collected and quickly transferred into a fresh tube. The RNA concentration and ratio was measured using a NanoDrop spectrophotometer (Thermo Scientific, Waltham, USA).

For cDNA synthesis, the beads were washed in $10 \mu \mathrm{L}$ QuantiTect $5 \times$ RT buffer. Afterwards they were suspended in $10 \mu \mathrm{L} 5 \times \mathrm{RT}$ buffer and $0.5 \mu \mathrm{L}$ QuantiTect Reverse Transcriptase. Synthesis took place for $15 \mathrm{~min}$ at $42^{\circ} \mathrm{C}$ and inactivation of transcriptase was carried out at $95^{\circ} \mathrm{C}$ for $3 \mathrm{~min}$. cDNA was used for quantitative analysis in a $\mathrm{qPCR}$ with primers specific for the Euglena gracilis housekeeping gene $\alpha$-Tubulin.

\subsection{Polymerase chain reaction}

PCR was carried out to check the quality of the transcribed cDNA and therefore also the quality of the trapped mRNA. $\alpha$ Tubulin was amplified with specific primers, which resulted in a $180 \mathrm{bp}$ long fragment. The PCR reactions were carried out in $25 \mu \mathrm{L}$ volume containing $0.4 \mathrm{mM}$ dNTPs; PCR Buffer: $20 \mathrm{mM}$ Tris- $\mathrm{HCl}, \mathrm{pH}$ 8.3, $100 \mathrm{mM} \mathrm{KCl}$ and $3 \mathrm{mM} \mathrm{MgCl}_{2}$; TaKaRa Taq: $1.25 \mathrm{U}$ (Premix Taq DNA Polymerase from Clonetech, Mountain View, USA); $20 \mu \mathrm{M}$ of each primer and template DNA in a thermal cycler (C1000 Touch, Bio-Rad, USA.) The PCR profile was as follows: $95^{\circ} \mathrm{C}$ for $30 \mathrm{~s}$ followed by 29 cycles of amplification at $95^{\circ} \mathrm{C}$ for $20 \mathrm{~s}, 58^{\circ} \mathrm{C}$ for $20 \mathrm{~s}$, $68^{\circ} \mathrm{C}$ for $20 \mathrm{~s}$ and with a final extension at $68^{\circ} \mathrm{C}$ for $5 \mathrm{~min}$. The PCR products were analyzed on a $1 \%$ agarose gel.

\subsection{Real time PCR analysis}

For real time PCR analysis the $180 \mathrm{bp}$ big fragment of $\alpha$-Tubulin was amplified using the QuantiFast SYBR Green PCR Kit from Qiagen (Cat.no. 204054). Total RNA was isolated and exactly $1 \mu \mathrm{g}$ was transcribed into cDNA. The real time PCR reactions were carried out in $25 \mu \mathrm{L}$ volume according to the manufacturer's recommendations. The PCR profile was as follows: $95^{\circ} \mathrm{C}$ for $30 \mathrm{~s}$ followed by 40 cycles of amplification at $95^{\circ} \mathrm{C}$ for $60 \mathrm{~s}, 60^{\circ} \mathrm{C}$ for $30 \mathrm{~s}$. A standard curve was used to determine the exact number of $\alpha$-Tubulin molecules $/ \mu \mathrm{L}$.

\section{Results and discussion}

Planning an experiment in molecular biology in space is not trivial. A number of factors influence the design of the procedures, like limited space and energy, and short or no crew time, to name the most obvious and challenging ones. Usually the conditions for storage and the actual performing of the analysis for our purposes greatly differ from the conditions recommended by the manufacturers, and they are not particularly eager to provide tests and consulting on non-nominal once-in-a-lifetime-experiments, which only cost money and have a poor monetary return value. Therefore, in this study the stability of mRNA isolation reagents over one year was evaluated to validate our approach on the analysis of molecular changes in Euglena during a long-term space flight. The major differences from the procedure recommended by the manufacturer are the storage temperature of $19^{\circ} \mathrm{C}$ instead of $4{ }^{\circ} \mathrm{C}$ (for energy reasons: cooling is impossible with the given power budget in our mission), and a combination of washing buffer, DTT and magnetic beads (for limited space and handling reasons, only one tank could be used). Initially selection of potential magnetic beads for proper mRNA trapping was carried out. To isolate messenger RNA, magnetic beads with a poly-dT tail were used to trap the polyadenylated mRNA specifically. Therefore, two different magnetic beads were tested for their ability to bind mRNA from Euglena gracilis. The beads were tested in normal Eppendorf tubes according to the manufacturer's recommendations and in a silicon tube. Data suggest that the Dynabeads can bind more mRNA from an equal amount of input than the MagJET beads (Fig. 1(A)). Moreover, the quality of RNA isolated with the Dynabeads was better compared to MagJET (Fig. 1(B)). Good quality RNA should show a value between 1.8 and 2 for the absorption ratio at 260 and $280 \mathrm{~nm}$.

Considering that only $1-5 \%$ of the total RNA content of cells is actually mRNA the magnetic poly-dT technologies is of great benefit since it targets only the mRNA molecules and pulls them directly out of solution. Compared to the common RNA isolation methods where up to $80 \%$ of the RNA yield is ribosomal RNA, the magnetic beads only isolate the mRNA free of contaminating ribosomal RNA, tRNA, miRNA, siRNA, non-Poly-A RNA and preprocessed RNA (Anonymous, 2016).

We found that $22 \mu \mathrm{L}$ of magnetic beads can bind up to $130 \mathrm{ng}$ mRNA of Euglena gracilis. This is important for planning further steps in gene expression analysis. There is no guarantee that an equal amount of magnetic beads will always bind the same amount of mRNA, but this will not impair the microarray based expression detection since several housekeeping genes will be used for normalization. After selecting the magnetic based bead system, it was necessary to choose an optimal buffer for the proper lysis of the Euglena cells before isolating mRNA. Therefore, three differ-
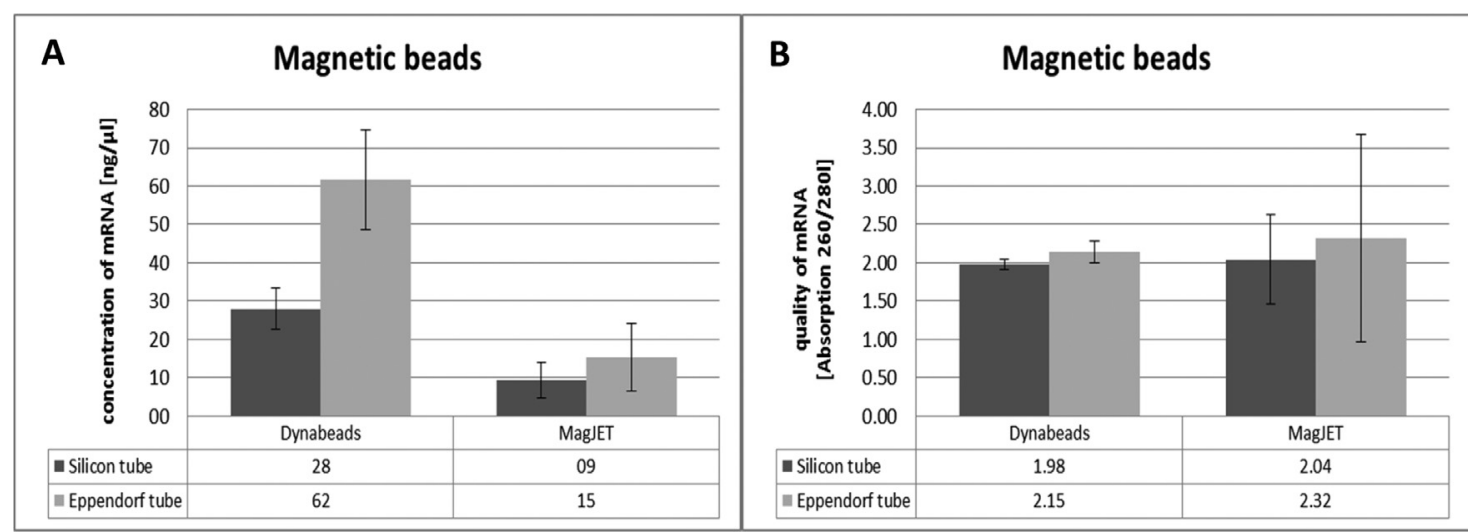

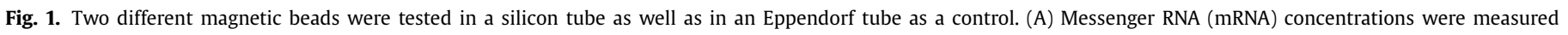
using NanoDrop spectrophotometer. (B) RNA-Quality was measured using NanoDrop spectrophotometer. 

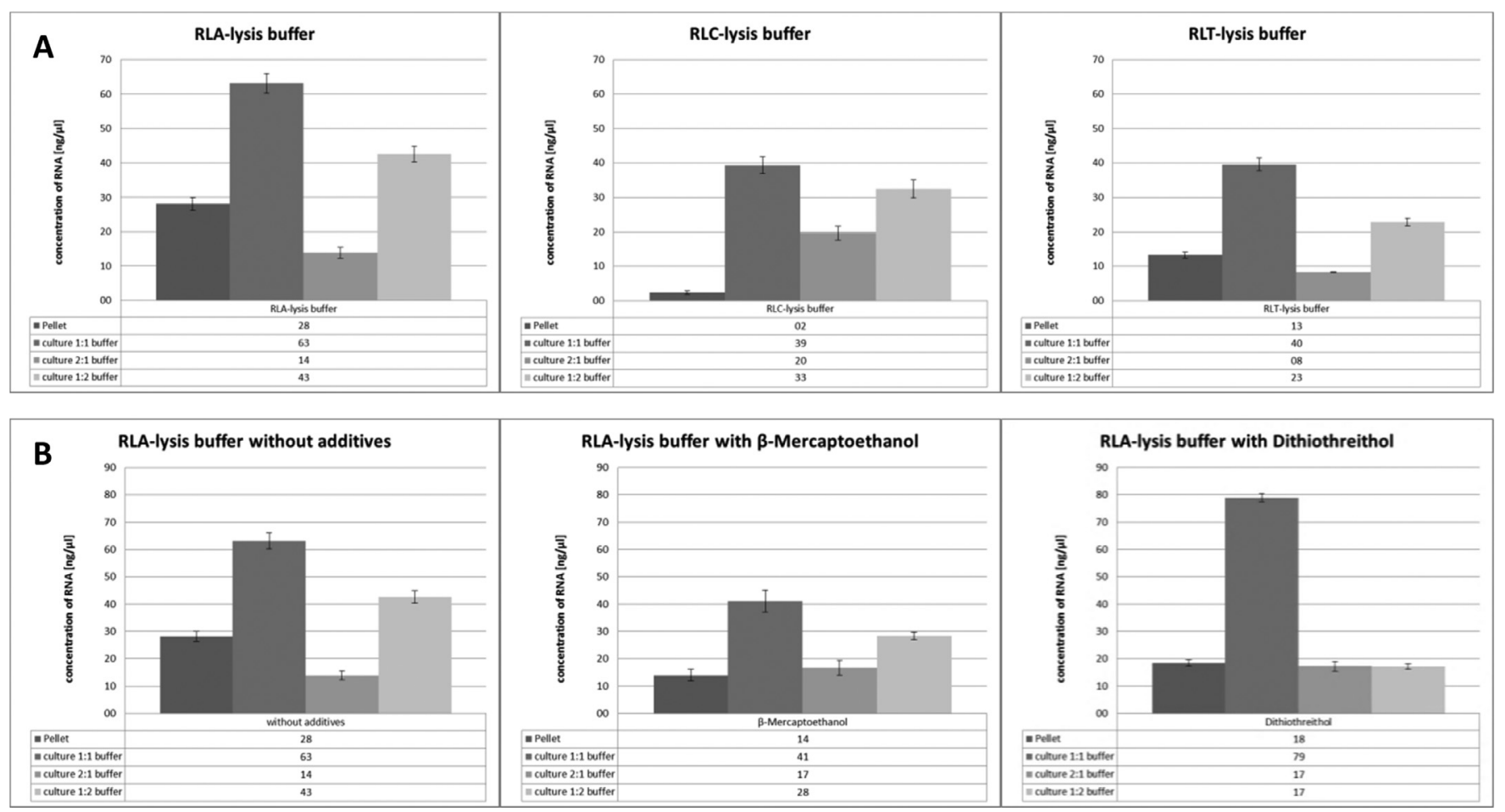

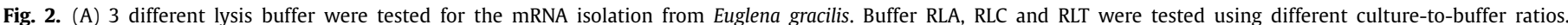

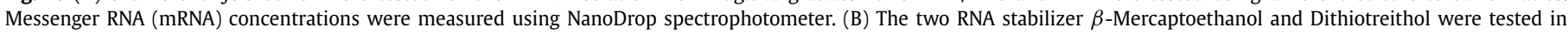
the RLA-lysis buffer in different culture-to-buffer ratio. Messenger RNA (mRNA) concentrations were measured using NanoDrop spectrophotometer.

ent lysis buffer RLA, RLC and RLT were tested at different bufferto-culture ratios. Cells were pelleted before lysis due to the manufacturer's recommendations and were used as a control. Since it is not possible to centrifuge cells in the satellite, we had to test the different buffer-to-culture ratios. Among the three, the RLAlysis buffer with the buffer-to-culture ratio of $1: 1$ was found to be ideal for yielding highest amount of RNA (Fig. 2(A)). Further experiments were then carried out using the RLA-lysis buffer. Next, a RNA stabilizer had to be found, since the incubation time needed for the proper binding of the magnetic beads with the mRNA is quite long, and the degradation of mRNA by RNAses is very fast. The RLA-lysis buffer was then mixed with the two different RNA stabilizer, DTT or $\beta$-Mercaptoethanol. Data indicates a higher RNA content when using DTT as RNA stabilizer with a buffer to culture ratio of $1: 1$ compared to $\beta$-Mercaptoethanol or without any additives (Fig. 2(B)). The higher yield in RNA concentration when using a buffer to culture ratio of 1:1 than using the cell pellet, according to the manufacturer's recommendations, is an advantage of the standard protocol. Although the company producing these magnetic beads claimed that the functionality of the Dynabeads would be impaired when using reducing agents like DTT, our results showed no such effect.

Finally, the effective incubation time of lysis buffer with the magnetic beads and Euglena gracilis cells with and without DTT had to be found. Therefore, RNA was isolated and same amounts of cDNA have been transcribed. The housekeeping gene $\alpha$-Tubulin was amplified in real time PCR to figure out the highest amount of molecules per $\mu \mathrm{L}$ of used cDNA (Fig. 3). The long incubation time of up to $240 \mathrm{~min}$ at room temperature with the addition of DTT seems to receive the highest amount of $\alpha$-Tubulin molecules compared to the other data.

After all this important pre-experiments it was finally possible to set up the stability test mixtures. And additionally, the long term stability of our different reagents at different temperatures was investigated. The RNA isolated with the stability test

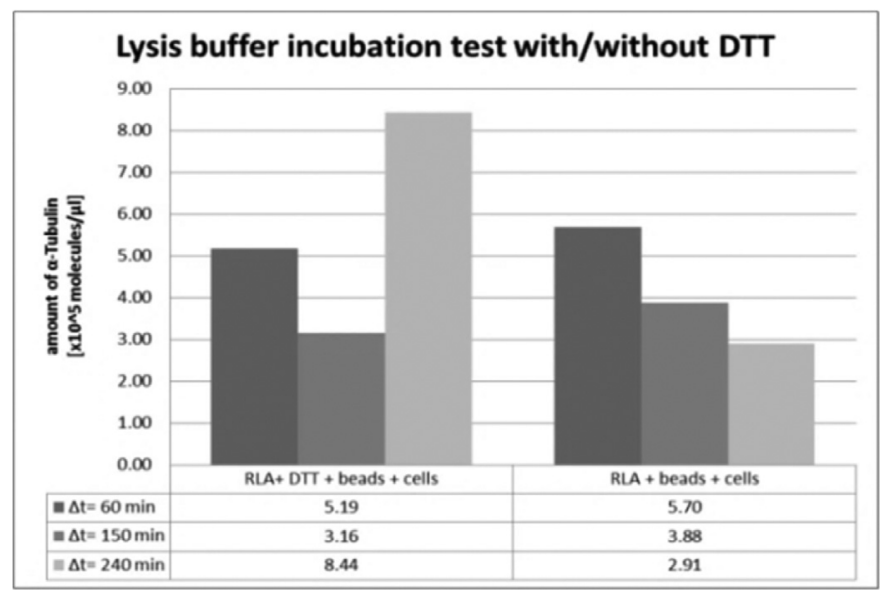

Fig. 3. RLA-lysis buffer incubation test. Real time PCR analysis of the housekeeping gene $\alpha$-Tubulin. The RLA-lysis buffer was incubated with $15 \mu \mathrm{L}$ beads and 35.500 cells, with or without the RNA stabilizer DTT for $60 \mathrm{~min}, 150 \mathrm{~min}$ and $240 \mathrm{~min}$. RNA was isolated, cDNA was transcribed and the amount of $\alpha$-Tubulin was achieved using real-time PCR.

mixture \#1 and separated on a 1\% agarose gel shows that the RNA yield is similar for all triplicates throughout the whole test (Fig. 4(1A) and (B)). After RNA isolation, the cDNA was transcribed and analyzed in PCR using the $\alpha$-Tubulin primers, which resulted in a $180 \mathrm{bp}$ long amplicon as expected. In stability test mixture \#1 there is a strong band both at the beginning of the test as well as at the end (Fig. 4(1C) and (D)). The same $\alpha$-Tubulin PCR was performed for stability test mixture \#2, where the intensity of the band is lower at the end of the test than at the beginning (Fig. 4(2A) and (B)), but this will be no problem in the end, since the gene expression analysis will be done using housekeep- 

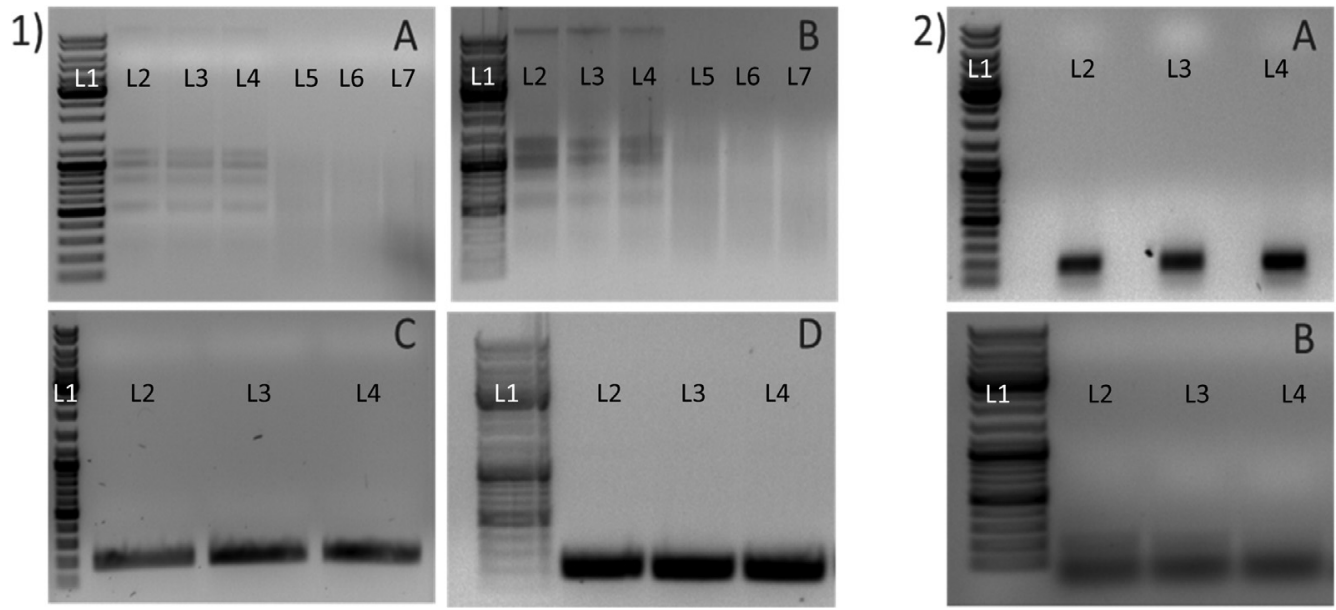

Fig. 4. (1) stability test mixture \#1: $1 \%$ agarose gel of RNA and CDNA quality and quantity, and PCR analysis with $\alpha$-Tubulin primers for a fragment of 180 bp. (A) RNA and cDNA on $\Delta t$ [0]. L1 Gene Ruler Mix (ThermoScientific), L2: RNA of isolation 1, L3: RNA of isolation 2, L4: RNA of isolation 3, L5: cDNA of isolation 1, L6: cDNA of isolation 2 and L7: cDNA of isolation 3. (B) RNA and cDNA on $\Delta t$ [455]. Lanes loaded as in (A). (C) PCR analysis with primers for $\alpha$-Tubulin on $\Delta t$ [0]. L1: Gene Ruler Mix (ThermoScientific), L2: PCR product isolation 1, L3: PCR product isolation 2 and L4: PCR product isolation 3. (D) PCR analysis with primers for $\alpha$-Tubulin on $\Delta \mathrm{t}$ [455]. Lanes loaded as in (C). (2) Stability test mixture \#2: PCR analysis with $\alpha$-Tubulin primers for a fragment of $180 \mathrm{bp}$. A) PCR analysis on $\Delta \mathrm{t}$ [0]. L1: Gene Ruler Mix (ThermoScientific), L2: PCR product isolation 1, L3: PCR product isolation 2 and L4: PCR product isolation 3. (B) PCR analysis on $\Delta t$ [360]. Lanes loaded as in 2 (A).

Table 1

Data of each measurement of stability test mixture \#1. Given is the date of isolation, the concentration of the isolation in $\mathrm{ng} / \mathrm{\mu L}$ and the $\mathrm{R}$ value $(=\mathrm{quality}$ ratio A260/A280, which should be between 1.8 and 2 for RNA). Mean percentage and standard deviation of the RNA concentration compared to the value at the start are also given.

\begin{tabular}{|c|c|c|c|c|c|c|c|c|c|}
\hline \multirow[t]{2}{*}{$\Delta \mathrm{t}$ [days] } & \multicolumn{2}{|l|}{ 1. Isolation } & \multicolumn{2}{|l|}{ 2. Isolation } & \multicolumn{2}{|l|}{ 3. Isolation } & \multirow[t]{2}{*}{ Mean } & \multirow[t]{2}{*}{ \% Percentage } & \multirow[t]{2}{*}{ Standard deviation } \\
\hline & $\mathrm{RNA}[\mathrm{ng} / \mu \mathrm{l}]$ & $\mathrm{R}$ & 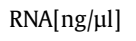 & $\mathrm{R}$ & $\mathrm{RNA}[\mathrm{ng} / \mu \mathrm{l}]$ & $\mathrm{R}$ & & & \\
\hline 0 & 39.3 & 1.96 & 39.6 & 1.99 & 39.6 & 1.98 & 39.50 & 100 & 0.17320508 \\
\hline 28 & 12 & 1.75 & 9.1 & 2.03 & 12.4 & 1.8 & 11.17 & 28 & 1.80092569 \\
\hline 42 & 34.4 & 1.97 & 26 & 2.1 & 32.1 & 1.88 & 30.83 & 78 & 4.34089085 \\
\hline 56 & 15.8 & 1.74 & 13.4 & 1.79 & 12.4 & 1.88 & 13.87 & 35 & 1.74737899 \\
\hline 70 & 23.5 & 2.07 & 19.4 & 1.91 & 16.3 & 1.99 & 19.73 & 50 & 3.61155553 \\
\hline 84 & 27.4 & 2 & 30.4 & 1.98 & 29.6 & 2.06 & 29.13 & 74 & 1.55349069 \\
\hline 98 & 22.8 & 1.75 & 23.4 & 1.95 & 21.3 & 1.91 & 22.50 & 57 & 1.08166538 \\
\hline 112 & 22.2 & 1.86 & 18 & 1.56 & 16.5 & 1.83 & 18.90 & 48 & 2.95465734 \\
\hline 126 & 19.5 & 1.79 & 21 & 1.76 & 19.6 & 1.72 & 20.03 & 51 & 0.83864971 \\
\hline 140 & 27.8 & 1.93 & 21.3 & 1.86 & 25 & 1.87 & 24.70 & 63 & 3.26036808 \\
\hline 154 & 26.3 & 1.85 & 19.9 & 1.79 & 21.5 & 1.81 & 22.57 & 57 & 3.3306656 \\
\hline 168 & 31.7 & 1.59 & 27.1 & 1.72 & 22.9 & 1.71 & 27.23 & 69 & 4.40151489 \\
\hline 183 & 28.8 & 1.92 & 30 & 1.91 & 27.8 & 1.87 & 28.87 & 73 & 1.10151411 \\
\hline 196 & 30 & 1.81 & 29.4 & 1.72 & 25.8 & 1.78 & 28.40 & 72 & 2.27156334 \\
\hline 224 & 14.8 & 1.69 & 15.2 & 1.66 & 16.3 & 1.73 & 15.43 & 39 & 0.77674535 \\
\hline 238 & 31.6 & 1.95 & 33.5 & 1.99 & 32.9 & 2.05 & 32.67 & 83 & 0.97125349 \\
\hline 252 & 17.5 & 1.76 & 17.2 & 1.77 & 12.3 & 1.68 & 15.67 & 40 & 2.91947484 \\
\hline 266 & 26.4 & 2 & 30.6 & 2.12 & 21 & 1.93 & 26.00 & 66 & 4.81248377 \\
\hline 280 & 51.2 & 2.06 & 56.5 & 2.02 & 53.5 & 2.03 & 53.73 & 136 & 2.65769324 \\
\hline 294 & 44.8 & 2.06 & 66.8 & 1.87 & 56.1 & 1.97 & 55.90 & 142 & 11.0013636 \\
\hline 308 & 44.1 & 1.81 & 46.3 & 1.86 & 37.35 & 1.71 & 42.58 & 108 & 4.66377887 \\
\hline 336 & 27.1 & 2.03 & 30.2 & 1.66 & 32.3 & 1.59 & 29.87 & 76 & 2.61597655 \\
\hline 351 & 27.5 & 1.94 & 34.25 & 1.67 & 30.5 & 1.91 & 30.75 & 78 & 3.38193731 \\
\hline 364 & 28.8 & 2.03 & 37.6 & 1.71 & 32.2 & 1.89 & 32.87 & 83 & 4.43771713 \\
\hline 378 & 18.5 & 1.96 & 38.6 & 1.6 & 29.7 & 1.67 & 28.93 & 73 & 10.0719081 \\
\hline 393 & 33.5 & 2.05 & 36 & 2.06 & 37.3 & 1.88 & 35.60 & 90 & 1.93132079 \\
\hline 406 & 33 & 1.6 & 24 & 1.64 & 20.5 & 1.86 & 25.83 & 65 & 6.44851404 \\
\hline 422 & 24 & 2.01 & 19.9 & 2.01 & 20.6 & 1.96 & 21.50 & 54 & 2.19317122 \\
\hline 444 & 15.7 & 1.99 & 17.1 & 1.87 & 20.4 & 1.99 & 17.73 & 45 & 2.41315837 \\
\hline 455 & 27.7 & 1.97 & 15.8 & 1.89 & 19.3 & 1.99 & 20.93 & 53 & 6.11582646 \\
\hline
\end{tabular}

ing gens where the difference in cDNA amount will be normalized with these genes.

Although there are high differences in the RNA content of stability test mixture \#1 (Table 1 and Fig. 5), the stability of the samples remained between $50-90 \%$ until the end of the test. The graph shows that there are also higher differences for the RNA content isolated with stability test mixture \#2 (Table 2, Fig. 6). Tables 1 and 2 show the mean values of the triplicates. In both tests, the $\mathrm{R}$ value is usually well within the limits. Obviously, the RNA concentration in Table 1 is much higher than in Table 2; this is due the fact that the total RNA was isolated in test \#1 using a total RNA Kit, while in test \#2 it is only the mRNA trapped by the magnetic beads. One major advantage using the Dynabeads is that the subsequent cDNA synthesis is directly performed on the beads since the Oligo-dT sequence cannot only be used to bind the mRNA but also act as a primer for the reverse transcriptase. 


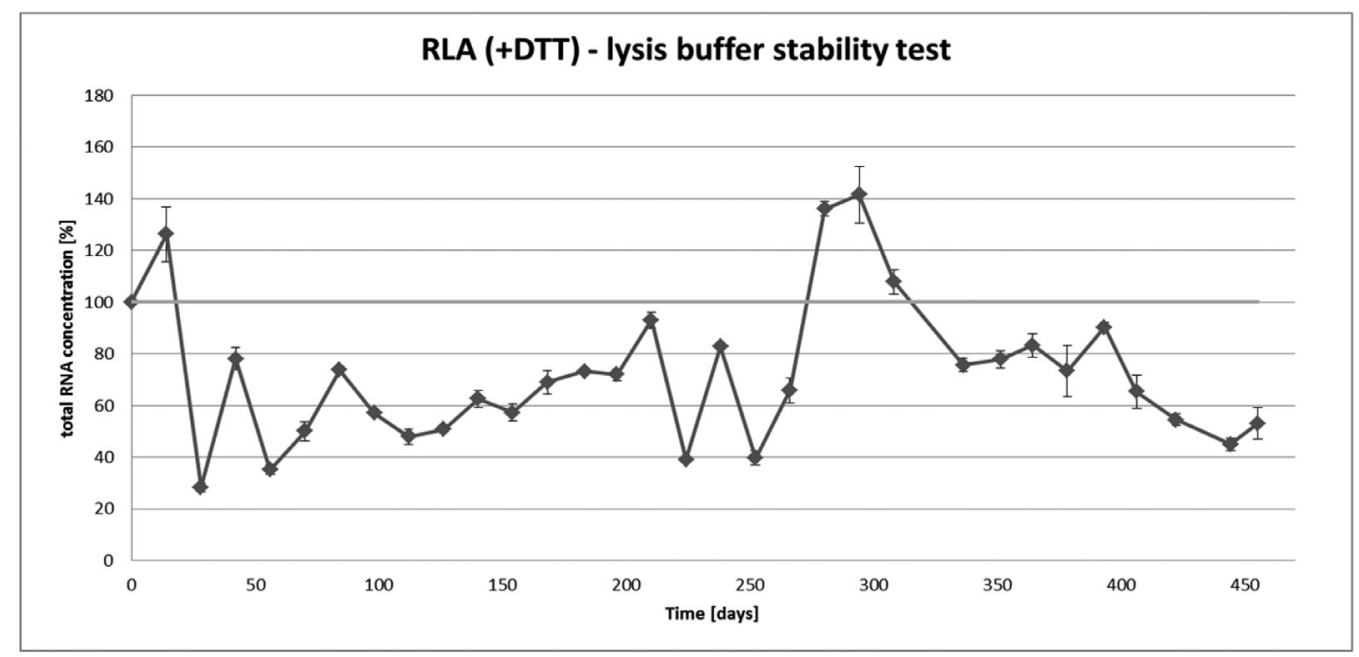

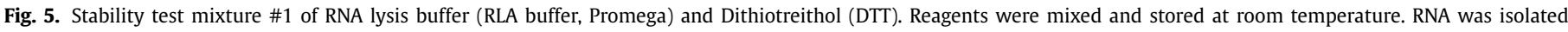
every 2 weeks and concentration was measured using the NanoDrop spectrophotometer.

Table 2

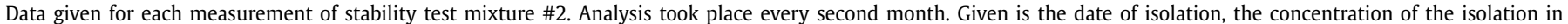

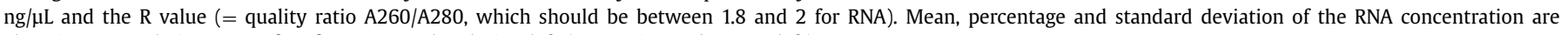
also given. 3. Isolation on $\Delta \mathrm{t}$ [360]: Not enough solution left ( $200 \mu \mathrm{L}$ instead $350 \mu \mathrm{L}$ left).

\begin{tabular}{|c|c|c|c|c|c|c|c|c|c|c|c|}
\hline$\Delta \mathrm{t}$ [days] & $\begin{array}{l}\text { 1. Isolation } \\
\text { RNA [ng/ul] }\end{array}$ & $\mathrm{R}$ & 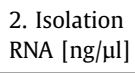 & $\mathrm{R}$ & 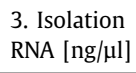 & $\mathrm{R}$ & Mean $4^{\circ} \mathrm{C}$ & Mean $19^{\circ} \mathrm{C}$ & $\% 4^{\circ} \mathrm{C}$ & $\% 19^{\circ} \mathrm{C}$ & Standard deviation \\
\hline 0 & 3.55 & 1.95 & 4.4 & 1.85 & 3.1 & 1.93 & 3.7 & 3.7 & 100.00 & 100.00 & 0.66 \\
\hline 59 & 2.1 & 1.62 & 3.1 & 1.72 & 3.1 & 1.71 & 2.8 & & 75.18 & & 0.58 \\
\hline 59 & 1.6 & 1.62 & 3.1 & 1.76 & 3.1 & 1.67 & & 2.6 & & 70.59 & 0.87 \\
\hline 122 & 4.3 & 1.75 & 7.6 & 1.97 & 7.4 & 1.95 & 6.4 & & 174.82 & & 1.85 \\
\hline 122 & 4.3 & 2.03 & 3.5 & 2.41 & 3.8 & 1.87 & & 3.9 & & 104.98 & 0.40 \\
\hline 178 & 3.7 & 1.79 & 4.1 & 1.85 & 3.1 & 1.88 & 3.6 & & 98.73 & & 0.50 \\
\hline 178 & 4.3 & 1.89 & 2.9 & 1.87 & 4.4 & 1.9 & & 3.9 & & 104.98 & 0.84 \\
\hline 241 & 6.1 & 1.93 & 5.3 & 1.91 & 3 & 1.85 & 4.8 & & 130.43 & & 1.61 \\
\hline 241 & 8.6 & 1.94 & 8.2 & 1.95 & 6.7 & 1.94 & & 7.8 & & 212.67 & 1.00 \\
\hline 290 & 3.5 & 1.71 & 3.9 & 1.97 & 4 & 1.82 & 3.8 & & 103.26 & & 0.26 \\
\hline 290 & 4.1 & 1.74 & 3.3 & 1.72 & 3.4 & 1.74 & & 3.6 & & 97.74 & 0.44 \\
\hline 360 & 3.9 & 1.78 & 3.9 & 1.76 & 4.45 & 1.89 & 4.1 & & 110.96 & & 0.32 \\
\hline 360 & 2.4 & 1.72 & 2.9 & 1.87 & 1.8 & 1.78 & & 2.7 & & 71.95 & 0.55 \\
\hline
\end{tabular}

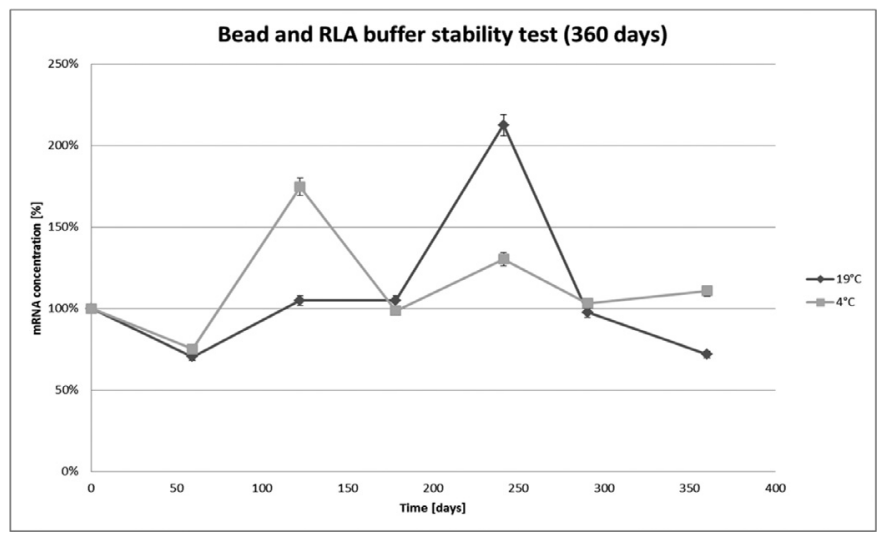

Fig. 6. Stability test mixture \#2 of RNA lysis buffer (RLA buffer, Promega) with Dithiotreithol (DTT) and Dynabeads ${ }^{\circledR}$ Oligo (dT) 25 magnetic beads (Invitrogen). Reagents were mixed and stored at $19^{\circ} \mathrm{C}$ (expected temperature) and at $4{ }^{\circ} \mathrm{C}$ as recommended by the manufacturer as a control. Messenger RNA (mRNA) was isolated every 2 month from a total RNA sample and concentration was measured using the NanoDrop spectrophotometer.

\section{Conclusion}

It can be claimed that the Dynabeads isolate more mRNA than the Magjet. Furthermore, the lysis of Euglena gracilis with RLA buffer worked best with the addition of DTT and a culture to buffer ratio of $1: 1$. The long incubation of the lysis buffer and the $E u$ glena cells for up to $240 \mathrm{~min}$ resulted in the highest yield of RNA. The long lasting stability of both the incubation of RLA-lysis buffer with the RNA stabilizer DTT (stability test mixture \#1) as well as the Dynabeads in the RLA-lysis buffer with DTT (stability test mixture \#2) was verified. Differences in the RNA concentration of the triplicates of the stability tests will be compensated in the experiment by proper controls.

\section{Acknowledgment}

The work was partially funded by the DLR on behalf of the BMBF [grant 50WB1528]. The work was conducted in the frame of a project "Utilization of $E$. gracilis in life-support systems". Ina Becker is a doctoral candidate of the Helmholtz Space Life Sciences Research School (SpaceLife), German Aerospace Center (DLR) Cologne, Germany, which was funded by the Helmholtz Association (Helmholtz-Gemeinschaft) over a period of six years (Grant No. $\mathrm{VH}-\mathrm{KO}-300$ ) and received additional funds from the DLR, including the Aerospace Executive Board and the Institute of Aerospace Medicine.

\section{References}

Anonymous. mRNA Isolation with Dynabeads in 15 minutes (accessed December 22, 2016). 
Braun, M., 2002. Gravity perception requires statoliths settled on specific plasma membrane areas in characean rhizoids and protonemata. Protoplasma 219, 150-159.

Checcucci, A, 1976. Molecular sensory physiology of Euglena. Naturwissenschaften 63 (9), 412-417.

Daiker, V, Häder, D-P, Richter, PR, Lebert, M, 2011. The involvement of a protein kinase in phototaxis and gravitaxis of Euglena gracilis. Planta 233 (5), 1055-1062.

Daiker, V, Lebert, M, Richter, P, Hader, D-P., 2010. Molecular characterization of a calmodulin involved in the signal transduction chain of gravitaxis in Euglena gracilis. Planta 231 (5), 1229-1236.

Ghetti, F, Colombetti, G, Lenci, F, Campani, E, Polacco, E, Quaglia, M, 1985. Fluorescence of Euglena gracilis photoreceptor pigment: an in vivo microspectrofluorometric study. Photochem. Photobiol. 42 (1), 29-33.

Häder, D-P., 1987. Polarotaxis, gravitaxis and vertical phototaxis in the green flagellate, Euglena gracilis. Arch. Microbiol. 147, 179-183.

Häder, D-P., Lebert, M., Richter, P., Ntefidou, M., 2003. Gravitaxis and graviperception in flagellates. Adv. Space Res. 31 (10), 2181-2186.

Häder, D-P., Richter, P.R., Strauch, S.M., Schuster, M., 2006. Aquacells - flagellates under long-term microgravity and potential usage for life support systems. Micrograv. Sci. Technol. 18, 210-214.

Häder, D-P., Rosum, A., Schäfer, J., Hemmersbach, R., 1995. Gravitaxis in the flagellate Euglena gracilis is controlled by an active gravireceptor. J. Plant Physiol. $146,474-480$.
Hemmersbach, R., Häder, D-P., 1999. Graviresponses of certain ciliates and flagellates. FASEB J 13, S69-S75.

Iseki, M., Matsunaga, S., Murakami, A., Ohno, K., Shiga, K., Yoshida, C., et al., 2002. A blue-light-activated adenylyl cyclase mediates photoavoidance in Euglena gracilis. Nature 415, 1047-1051 On CD1.

Nasir, A., Strauch, S.M., Becker, I., Sperling, A., Schuster, M., Richter, P.R., et al., 2014 The influence of microgravity on Euglena gracilis as studied on Shenzhou 8. Plant biol. 16 (1), 113-119 (Stuttgart, Germany).

Ntefidou, M., Iseki, M., Watanabe, M., Lebert, M., Häder, D-P., 2003. Photoactivated adenylyl cyclase controls phototaxis in the flagellate Euglena gracilis. Plant Physiol. 133 (4), 1517-1521.

Richter, P.R., Lebert, M., Tahedl, H., Häder, D-P., 2001. Physiological characterization of gravitaxis in Euglena gracilis and Astasia longa studied on sounding rocket flights. Adv. Space Res. 27, 983-988.

Strauch, S.M., Richter, P., Schuster, M., Häder, D-P., 2010. The beating pattern of the flagellum of Euglena gracilis under altered gravity during parabolic flights. J. Plant physiol. 167 (1), 41-46.

Wayne, R., Staves, M.P., Leopold, A.C., 1992. The contribution of the extracellular matrix to gravisensing in characean cells. J. Cell Sci. 101, 611-623. 